\title{
Incisor inclination and arch width changes following mandibular setback surgery for correction of mandibular prognathism
}

\author{
Fang Ning ${ }^{1}$, Yinzhong Duan ${ }^{2}$, Yi Xue ${ }^{1}$, Donghui Yuan ${ }^{1}$ \\ ${ }^{1}$ Department of Stomatology, Bethune international Peace Hospital(Of The People's Liberation Army), Shijiazhuang City, Hebei Province, \\ People's Republic of China, 050082 \\ ${ }^{2}$ Department of Orthodontics, School of Stomatology, The Fourth Military Medical University, Xi'an City, Shaanxi Province, People's \\ Republic of China, 710032
}

Email address:

ningfang327@163.com (Fang Ning)

\section{To cite this article:}

Fang Ning, Yinzhong Duan, Yi Xue, Donghui Yuan. Incisor Inclination and Arch Width Changes Following Mandibular Setback Surgery for Correction of Mandibular Prognathism. Clinical Medicine Research. Vol. 3, No. 6, 2014, pp. 181-188. doi: 10.11648/j.cmr.20140306.15

\begin{abstract}
Purpose: The aim of this study was to investigate and evaluate the changes of incisor inclination and arch width in the surgical-orthodontic treatment to correct a Class III malocclusion resulting from skeletal mandibular prognathism. Materials and methods: The skeletal mandibular prognathism subjects consisted of 25 males and 20 females (mean age:22.8 $\pm 4.2 y e a r s$ ). A lateral cephalogram was taken for each subject before preoperative orthodontic treatment (T1), presurgical (T2), and at completion of the postoperative orthodontic treatment (T3). Skeletal and dental values and arch width measurements at T1, T2 and T3 were obtained. Each cephalogram was traced and digitized twice. For statistical evaluation, all the data were expressed as Mean \pm Standard deviation and analyzed with SPSS software. Results: At pretreatment, dental compensation was normally found in both dental arches, including anterior and posterior teeth. During presurgical orthodontic treatment, most of the patient's mandibular incisors were significantly decompensated $(\mathrm{P}<0.05)$, while no significant changes were noted in the maxillary incisors $(\mathrm{P} \geq 0.05)$. The increase in maxillary inter-first molar width were statistically significant $(\mathrm{P}<0.05)$. With effective dental decompensation, the relationship between teeth and basal bone was improved obviously. It is beneficial for moving bone bulk in surgery. After the surgery, most of the patients (97.8\%) finished with proper overjet and overbite, establish stable and harmony occlusion. Conclusion: By effective and proper dental decompensation, desired teeth positions could be achieved before surgery, which could lead to better surgical results.
\end{abstract}

Keywords: Dental Decompensation, Skeletal Madibular Prognathism, Orthognathic Surgery, Class III Malocclusion, Harmony Occlusion

Mandibular prognathism, a skeletal disharmony commonly associated with Class III malocclusion [1], is one of the most frequent skeletal discrepancies for which patients request treatment in clinical practice in China. It greatly affects patients' appearance, speech, mastication and the psychological health. There are three main treatment options for mandibular prognathism patients: growth modification, orthodontic camouflage treatment and surgical-orthodontic treatment. Growth modification should be commenced before the pubertal growth spurt and impossible after this spurt [2]. As for the adult skeletal mandibular prognathism patients, mild to moderate cases can often be treated with orthodontics camouflage treatment. However, patients with severe mandibular prognathism discrepancies are often treated with surgical-orthodontic treatment to gain functional and facial esthetic improvement $[3,4]$.

Surgical-orthodontic treatment of nongrowing mandibular prognathism patients includes presurgical orthodontic treatment to decompensate the malocclusion, surgical correction of the skeletal discrepancy, and postsurgical detailing and finishing of the occlusion [3]. Many mandibular prognathism cases exhibit compensation phenomenon, such as excessive labial inclination of upper incisor teeth and excessive lingual inclination of lower incisor teeth [5]. The compensation phenomenon in the posterior teeth is also existed. For example, the buccal upper molars or the lingual lower molars. The truth that dental 
decompensation should be done before orthognathic surgery is a common knowledge for the orthodontics. The quality of decompensation before surgery will greatly influence the surgery process such as the dimension of the bone bulk movement and the effects of surgery [6]. However, what degree could the incisor inclination and arch width changes achieve? Johnston et al [3] studied the effects of presurgical incisor position on quality and quantity of Class III skeletal surgical correction. In this sample, most patients achieved normal overjet, but the skeletal improvement was not as successful, with only forty percent having a normal ANB angle at posttreatment. Fifty-two percent still had excessive SNB angles after treatment. Frequently, presurgical incisor decompensation was not to normal values, with both maxillary and mandibular incisors still remaining compensated; this limited the skeletal surgical correction. The result of this study emphasized the importance of dental decompensation for patients with mandibular prognathism. However, what is the criterion for the appropriate dental decompensation? Whether the ANB angle must achieve normal after treatment? Also, what are the changes of incisor inclination and arch width before and after surgery? Few studies have reported this content with Chinese samples.

The aim of this study was: (1) evaluate the changes of incisor inclination and arch width before and after surgery for skeletal mandibular prognathism patients. (2) find the criterion for what is the approprite dental decompensation.

\section{Materials and Methods}

Cases selection: 45 skeletal mandibular prognathism patients (25 males and 20 females) treated with surgical-orthodontics in the department of orthodontics at Fourth Military Medical University were included in this study. The patients first visit dates were all between 2007.Jan to 2010 .Dec. The study protocol was approved by the Ethics Committee of the Fourth Military Medical University. Criteria for selection of subjects were as follow:

(1) Diagnosis of severe Class III skeletal malocclusion with prominent mandibular prognathism in a nongrowing adult.

(2) Treatment with mandibular setback surgery for the correction of mandibular prognathism.

(3) Availability of technically satisfactory lateral cephalometric radiographs and study model at time points before preoperative orthodontic treatment (T1), presurgical (T2), and at completion of the postoperative orthodontic treatment (T3).

The ages of the patients ranged from 17.8 to 32.4 years with a mean age of 22.8 years. For all the patients, the pretreatment lateral cephalometric radiographs indicated that SNA angle was in the normal range while SNB ranged from 83.2 to 88.5 degrees and was significantly over 80 degrees. So the diagnosis of skeletal mandibular prognathism was made. Before surgery, orthodontic treatment was all needed to achieve active decompensation.

\subsection{Cephalometric Analysis}

The lateral cephalometric radiographs and study model were acquired for each subject before preoperative orthodontic treatment (T1), presurgical (T2), and at completion of the postoperative orthodontic treatment (T3). Each radiograph used in the present study was taken in the same cephalostat and traced on acetate paper. Thirteen cephalometric landmarks (Figure 1,2) and maxillary and mandibular interarch measurements (Figure 3) were identified [4,7-9]. All the tracings and measurements were manually carried out twice with a 2 -week interval by one examiner with a sharp pencil under optimal conditions. The method error in locating, superimposing and measuring the changes of different landmarks was calculated by the Dahlberg's formula $M e=\sqrt{\sum d^{2} / 2 n}$, where $\mathrm{d}$ represents the difference between two registrations and $\mathrm{n}$ is the number of duplicate registrations. The method error determined was $0.3 \mathrm{~mm}$ for linear measurement and $0.4^{\circ}$ for angular measurement, which were both statistically insignificant $(\mathrm{P} \geq 0.05)$.

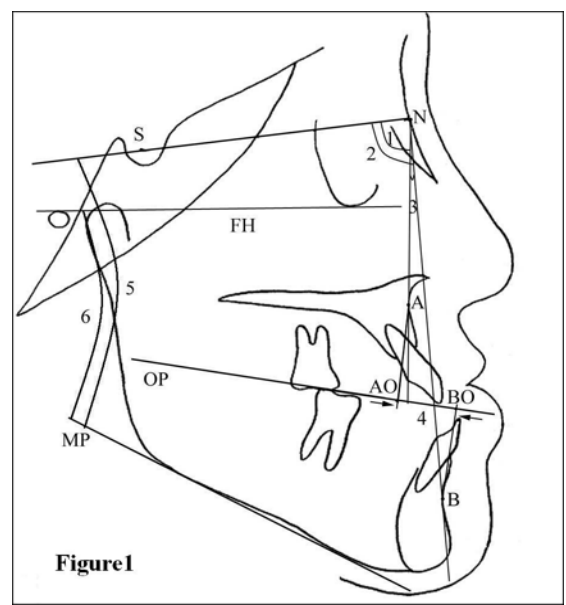

Figure 1. Skeletal measurements used in the study 1.SNA, 2.SNB, 3.ANB, 4.Wits, 5.SN-MP, 6.FMA.

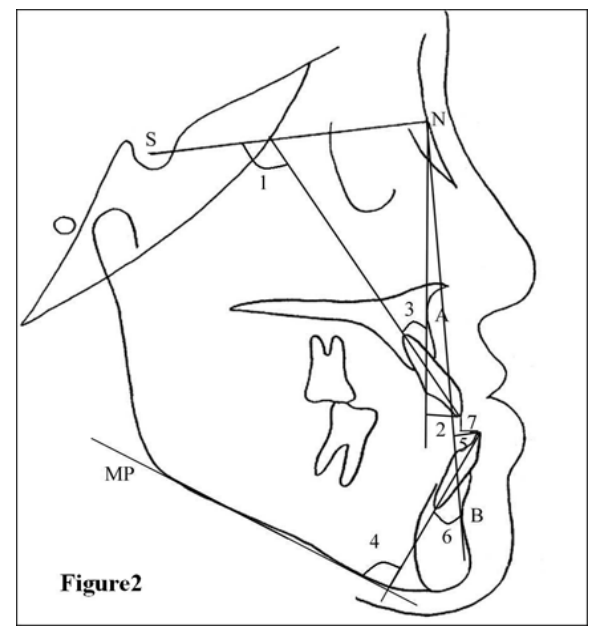

Figure 2. Dental measurements used in the study 1. U1-SN, 2. U1-NA(mm), 3. U1-NA $\left(^{\circ}\right)$, 4. IMPA, 5. L1-NB(mm), 6. L1-NB( $\left(^{\circ}\right)$, 7. Overjet(mm). 


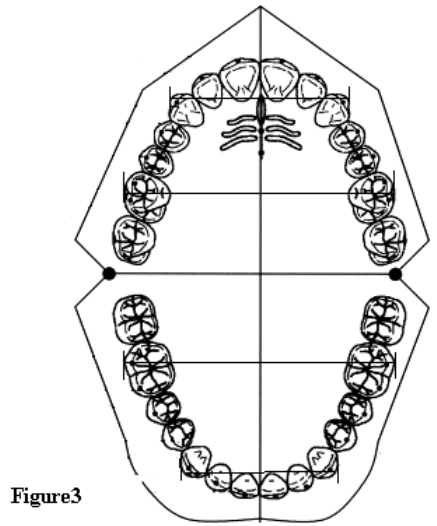

Figure 3. Maxillary and mandibular interarch measurements

\subsection{Statistical Methods}

The statistical analysis was processed with SPSS 10.0 for Windows. The arithmetic mean and standard deviation were calculated for each variable. Paired $t$-tests were performed to assess the statistical significance of any dental and skeletal change. The levels of significance were: $P \geq 0.05$ (NS), ${ }^{*} P<$ 0.05 .

\section{Results}

At the end of the treatment, most of the patients $(97.8 \%)$ finished with proper overjet and overbite, establish stable and harmony occlusion. Only one patient finished with shallow overjet and overbite.

\subsection{Dental Compensation Occurrence}

Dental compensation is general in the cases of skeletal mandibular prognathism as shown in table 1 . It can exist in maxilla, mandible, anterior and posterior teeth at the same time. Crowding is often obvious in mandible of anterior region.

Table 1. Dental compensation occurrence of skeletal mandibular prognathism

\begin{tabular}{lll}
\hline Dental compensation types & Number & Percent \\
\hline Labial inclination of upper incisor teeth & $40 / 45$ & 88.9 \\
Lingual inclination of lower incisor teeth & $44 / 45$ & 97.8 \\
Buccal inclination of upper posterior teeth & $35 / 45$ & 77.8 \\
Lingual inclination of lower posterior teeth & $43 / 45$ & 95.6 \\
Upper arch crowding & $23 / 45$ & 51.1 \\
Lower arch crowding & $39 / 45$ & 86.7 \\
\hline
\end{tabular}

\subsection{Skeletal and Dental Changes}

At T1, the SNA angle was within normal range, SNB angle was over the normal range and ANB angle was below the normal range. It was indicated that all the cases were diagnosed as skeletal mandibular prognathisms. After about 7.5 months to one and a half year of orthodontics treatment before surgery (T2), the positions of upper and lower teeth to basal bone were improved greatly as shown in Table 2 . The IMPA angle altered significantly after decompensation $(\mathrm{P}<0.05)$ and more approach to the norm. The L1-NB $(\mathrm{mm})$ and L1-NB (degree) increased $(\mathrm{P}<0.05)$. Reverse overjet of anterior teeth increased significantly after decompensation $(\mathrm{P}<0.05)$, while SNA, SNB, ANB, SN-MP, FMA angles and Wits $(\mathrm{mm})$ did not change significantly. That meant that decompensation did not alter the relationship of basal bone in upper and lower jaws. At T3, SNB, ANB, SN-MP, FMA angles and Wits $(\mathrm{mm})$ altered significantly after surgical treatment. The L1-NB (mm) and L1-NB (degree) decreased $(\mathrm{P}<0.05)$ compared with $\mathrm{T} 2$. The overjet was normal after surgical treatment.

Table 2. Skeletal and dental measures of the patients at T1, T2, T3: means, standard deviations, significant differences at different time points.

\begin{tabular}{|c|c|c|c|c|c|c|c|c|c|}
\hline \multirow{2}{*}{ Measure } & \multicolumn{2}{|l|}{$T 1$} & \multicolumn{2}{|l|}{$T 2$} & \multicolumn{5}{|l|}{$T 3$} \\
\hline & Mean & $S D$ & Mean & $S D$ & Mean & $S D$ & $T 1-2$ & $T 2-3$ & $T 1-3$ \\
\hline $\mathrm{SNA}\left({ }^{\circ}\right)$ & 82.5 & 4.2 & 82.6 & 4.1 & 82.6 & 4.1 & NS & NS & NS \\
\hline $\mathrm{SNB}\left(^{\circ}\right)$ & 86.7 & 4.5 & 86.7 & 4.6 & 83.0 & 4.9 & NS & $*$ & $*$ \\
\hline $\mathrm{ANB}\left({ }^{\circ}\right)$ & -4.2 & 3.1 & -4.1 & 2.9 & -0.4 & 2.9 & NS & $*$ & $*$ \\
\hline Wits(mm) & -10.1 & 6.2 & -9.9 & 6.8 & -5.2 & 4.3 & NS & $*$ & $*$ \\
\hline $\mathrm{SN}-\mathrm{MP}\left({ }^{\circ}\right)$ & 35.9 & 5.2 & 35.8 & 5.1 & 38.9 & 4.9 & NS & $*$ & $*$ \\
\hline $\mathrm{U} 1-\mathrm{SN}\left({ }^{\circ}\right)$ & 110.3 & 6.2 & 109.7 & 5.4 & 109.9 & 5.3 & NS & NS & NS \\
\hline U1-NA(mm) & 8.4 & 3.8 & 7.9 & 4.1 & 7.8 & 4.0 & NS & NS & NS \\
\hline $\mathrm{U} 1-\mathrm{NA}\left({ }^{\circ}\right)$ & 32.3 & 7.8 & 32.0 & 6.7 & 32.0 & 6.8 & NS & NS & NS \\
\hline $\operatorname{IMPA}\left({ }^{\circ}\right)$ & 81.7 & 6.5 & 91.2 & 5.7 & 89.8 & 6.3 & $*$ & NS & $*$ \\
\hline L1-NB(mm) & 5.1 & 2.3 & 6.0 & 2.5 & 5.2 & 2.0 & $*$ & $*$ & NS \\
\hline $\mathrm{L} 1-\mathrm{NB}\left({ }^{\circ}\right)$ & 19.8 & 5.9 & 23.5 & 6.4 & 20.1 & 5.7 & $*$ & $*$ & NS \\
\hline Overjet(mm) & -2.5 & 1.3 & -5.4 & 2.5 & 2.5 & 1.8 & * & * & $*$ \\
\hline
\end{tabular}

NS: $P \geq 0.05 *: P<0.05$.

\subsection{Arch Width Changes}

The Maxillary intercanine width and mandibular intercanine width and inter-first molar width did not change significantly at different time points. The increase in maxillary inter-first molar width were statistically significant $(\mathrm{P}<0.05)$ before and after dental decompensation of orthodontic treatment as shown in Table 3. 
Table 3. Maxillary and mandibular intercanine and inter-first molar arch width averages and standard deviations (SD) of the patients at T1, T2, T3:

\begin{tabular}{|c|c|c|c|c|c|c|c|c|c|}
\hline \multirow{2}{*}{ Measure } & \multicolumn{2}{|l|}{$T 1$} & \multicolumn{2}{|l|}{$T 2$} & \multicolumn{5}{|l|}{$T 3$} \\
\hline & Mean & $S D$ & Mean & $S D$ & Mean & $S D$ & $T 1-2$ & $T 2-3$ & $T 1-3$ \\
\hline Maxillary intercanine width & 37.5 & 2.7 & 38.5 & 2.1 & 38.2 & 1.9 & NS & NS & NS \\
\hline Maxillary inter-first molar width & 53.5 & 6.4 & 58.4 & 5.8 & 58.1 & 6.7 & * & NS & * \\
\hline Mandibular intercanine width & 32.3 & 1.9 & 33.1 & 2.3 & 32.9 & 2.0 & NS & NS & NS \\
\hline Mandibular inter-first molar width & 53.0 & 4.3 & 54.5 & 3.9 & 54.2 & 4.0 & NS & NS & NS \\
\hline
\end{tabular}

NS: $P \geq 0.05 *: P<0.05$.

\section{Case Report (Figure4-15)}

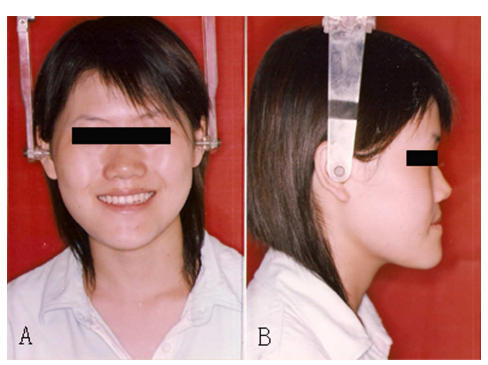

Figure 4. Pretreatment facial photographs A: Frontal view, B: Lateral view

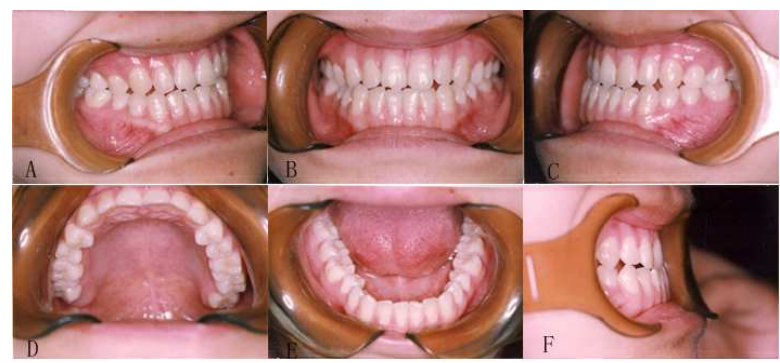

Figure 5. Pretreatment intraoral photographs A: Lateral view on the right side, B: Frontal view, C: Lateral view on the left side, D: Occlusal view of maxillary dentition, E: Occlusal view of mandibular dentition, F: Lateral view of the anterior teeth

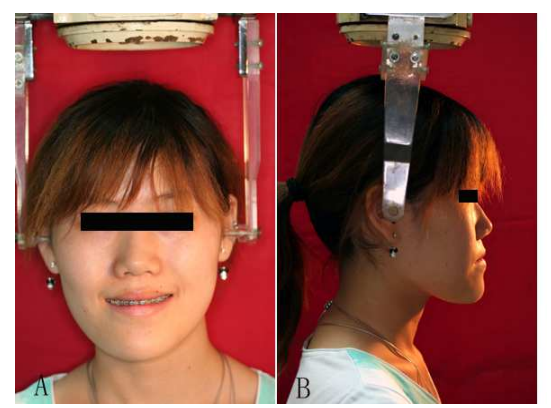

Figure 6. Presurgical facial photographs A: Frontal view, B: Lateral view

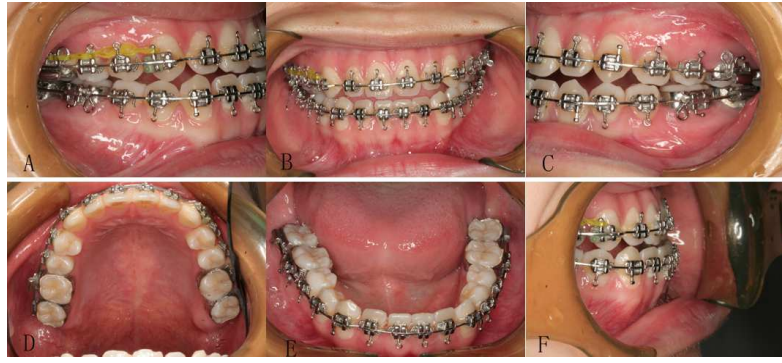

Figure 7. Presurgical intraoral photographs A: Lateral view on the right side, $B$ : Frontal view, $C$ : Lateral view on the left side, D: Occlusal view of maxillary dentition, E: Occlusal view of mandibular dentition, F: Lateral view of the anterior teeth
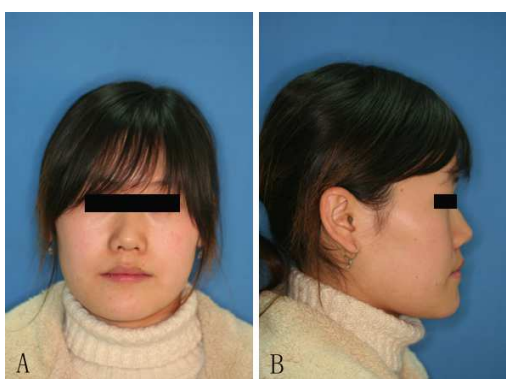

Figure 8. Posttreatment facial photographs A: Frontal view, B: Lateral view

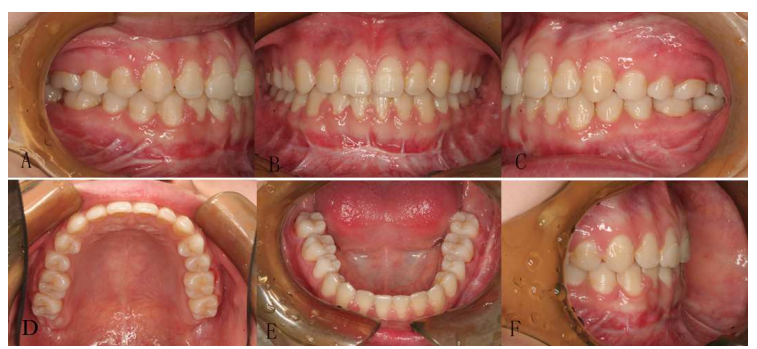

Figure 9. Posttreatment intraoral photographs A: Lateral view on the right side, B: Frontal view, C: Lateral view on the left side, D: Occlusal view of maxillary dentition, E: Occlusal view of mandibular dentition, F: Lateral view of the anterior teeth
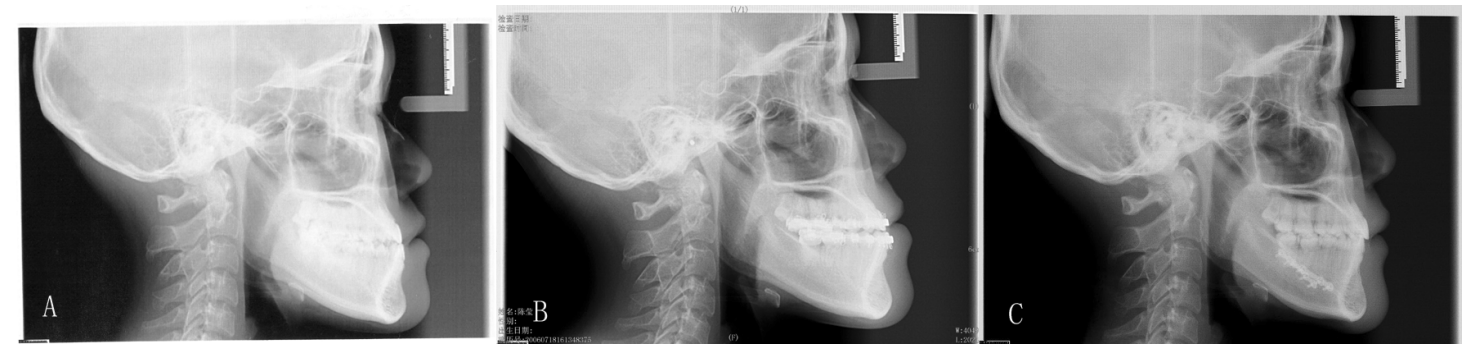

Figure 10. Lateral cephalographs A: Pretreatment, B: Presurgical, C: Posttreatment 

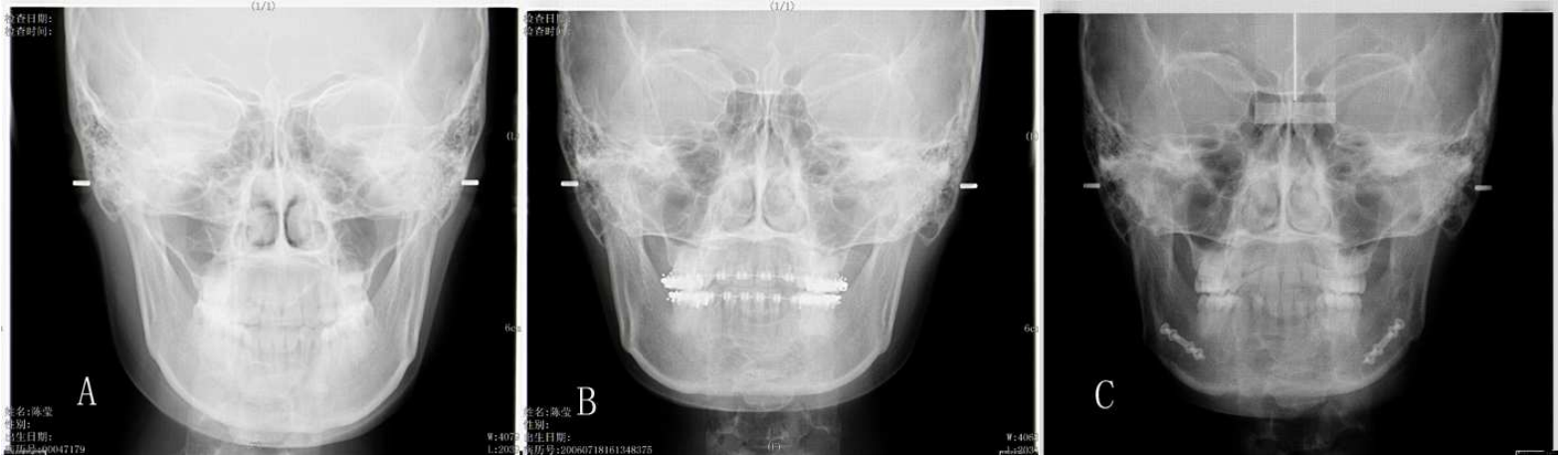

Figure 11. Posterioanterior position radiographs A: Pretreatment, B: Presurgical, C: Posttreatment
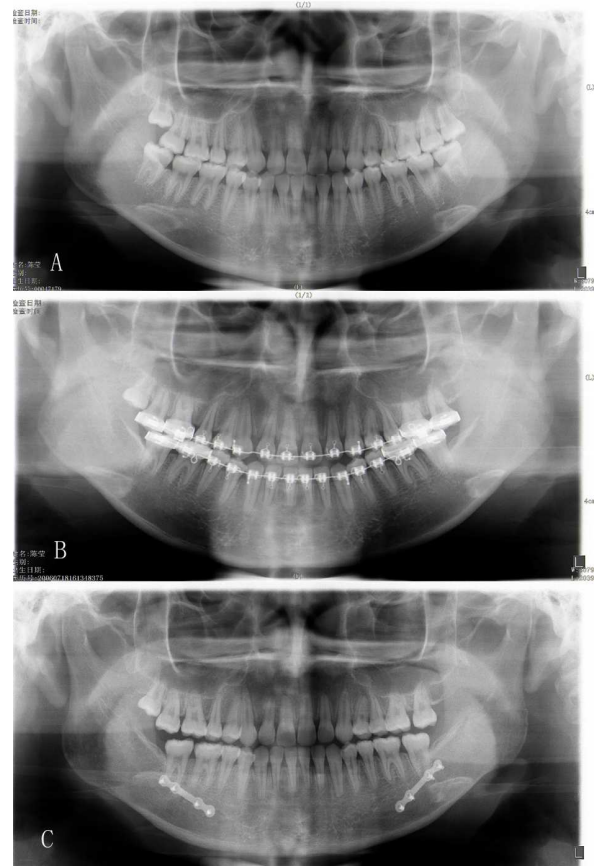

Figure 12. Panoramic radiographs A: Pretreatment, B: Presurgical, C: Posttreatment

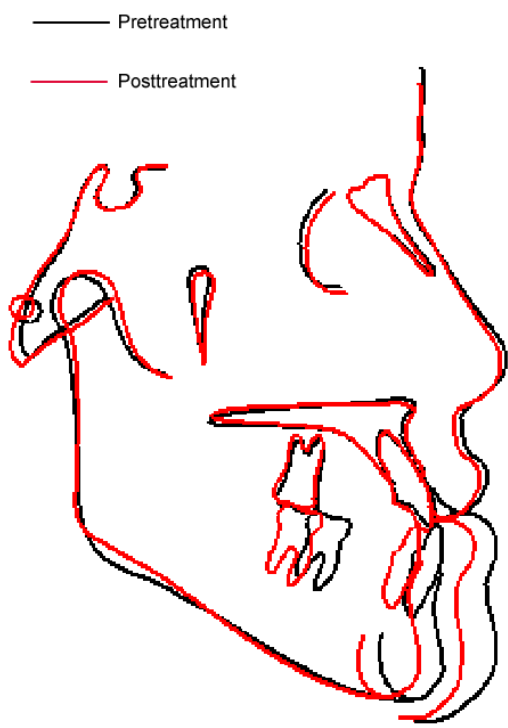

Figure 13. Superimposition of pretreatment and posttreatment cephalometric tracings

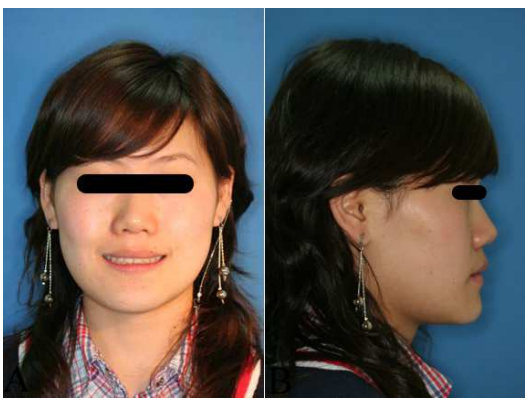

Figure 14. Three year later after finishing the treatment, the facial photographs A: Frontal view, B: Lateral view

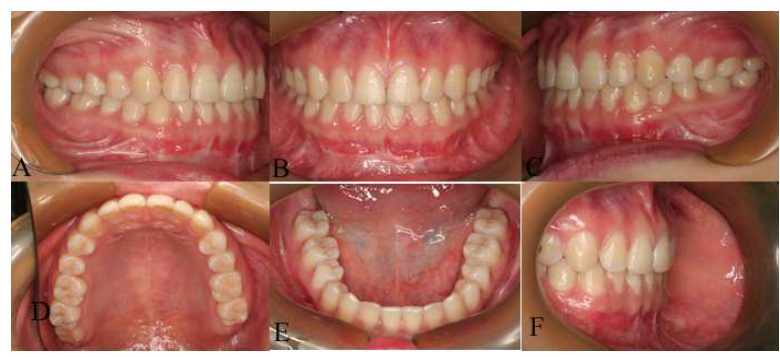

Figure 15. Three year later after finishing the treatment, the intraoral photographs A: Lateral view on the right side, B: Frontal view, C: Lateral view on the left side, D: Occlusal view of maxillary dentition, E: Occlusal view of mandibular dentition, F: Lateral view of the anterior teeth

\subsection{Case History}

A female aged 18 years with a concave profile sought for orthodontic treatment at the Department of Orthodontics of the Fourth Military Medical University. The intraoral examination showed a typical Class III molar relationship on both sides. The patient had an anterior crossbite with $-1.0 \mathrm{~mm}$ of overjet and $0 \mathrm{~mm}$ of overbite. There was no crowding in her upper arch and $2 \mathrm{~mm}$ crowding in the lower arch. Her maxillary midline deviated $2 \mathrm{~mm}$ toward left side, but the mandibular midline was concordant with facial midline. The maxillary incisors were relatively upright and the mandibular incisors were severely lingual inclined. The upper posterior teeth were buccal inclined and the lower posterior teeth were lingual inclined. A cephalogram indicated a Class III skeletal discrepancy $\left(\mathrm{ANB}=-3.5^{\circ}\right)$ with the maxilla positioned normally and the mandible positioned anteriorly relative to the cranial base $\left(\mathrm{SNA}=82.5^{\circ}, \mathrm{SNB}=86^{\circ}\right)$. There was no sign of active periodontal disease or temporomandibular disorders. 


\subsection{Treatment Planning and Procedures}

A joint orthodontic/orthognathic approach was adopted to achieve the following goals:

1. Orthodontic leveling, alignment and decompensation of the upper and lower teeth.

2. Bilateral sagittal split osteotomies for set back of the mandible to reduce the mandibular prognathism.

3. Achieve a Class I molar relationship and proper overjet and overbite, establish stable and harmony occlusion, correct deviated midlines, and improve function and aesthetics.

The MBT straight wire appliance was used after extraction of the two lower third molars and one upper third molar. The procedures were started from mandible. In order to get rid of the impeding of occlusion to buccal movement of lower teeth, the upper bite-plate was made. Decompensations of lower posterior lingual tipping teeth were achieved mainly through mandibular expansion. Furthermore, after the expansion, the mandibular dental arch was maintained by fixed lingual arch. The maxillary treatment was started after removing occlusion interference. After 6 months of decompensation procedures in maxilla and mandible, the lower incisors were upright and the overjet was increased to $-5 \mathrm{~mm}$. The upper and lower posterior teeth were completely decompensated. Presurgical orthodontics lasted 10 months. Surgery to the mandible was then performed. Postsurgical orthodontics lasted 4 months and the proper overbite and overjet were achieved. The ANB angle was changed from $-3.5^{\circ}$ to $0.5^{\circ}$ and the facial profile was improved significantly.

\section{Discussion}

\subsection{The Importance of Decompensation in the Anterior and Posterior Teeth}

Skeletal mandibular prognathism might be the result of excessive mandibular growth [10-12] and/or a changed growth pattern with an obtuse gonial angle $[1,13,14]$, and there is a probable interaction with structural changes of the cranial base $[15,16]$. Its etiology is not completely clear. Genetic factors, modulated by endocrinous and environmental factors, are the most concrete hypothesis for its origins [15-19]. Presurgical orthodontics treatment is an effective method for this kind of malocclusion and helps a lot in approving surgical results. Dental decompensation plays an important role in the procedure and should be given special attention.

In the process of mandibular development of mandibular prognathism patients, the sagittal ratio grew out of harmony. In order to overcome the influence of mandibular overgrowing to occlusion and maintain masticatory function, the lower anterior teeth gradually leaned lingually while the upper anterior teeth leaned labially. At the posterior region of dentition, in order to adapt to mandibular prognathism, the upper posterior teeth leaned bucally while the lower posterior teeth leaned lingually and the width of lower arch decreased. These phenomenons are teeth compensation [20]. In this study, teeth compensation almost existed in every case as the Table 1. The objective of decompensation is to improve the relationship between teeth and basal bone. If not, the retrusion of mandibular will be limited, especially in monomaxillary surgery and it is difficult to get the normal relationship in upper and lower incisors. Further more, if the mandible is retruded to the normal position without effective decompensation process, occlusion disorder will occur and recurrence becomes easily [21].

\subsection{Investigation of the Incisor Inclination and Arch Width Changes for Skeletal Mandibular Prognathism Patients after Surgery}

Dental compensation actually is the inclination change of lower and upper teeth toward basal bone. Cephalometric analysis is a commonly used method to evaluate dental compensation. The results can vary with different survey items selected. The examining items for upper and lower anterior teeth inclination in this study include U1-SN angle, U1-NA dimension, U1-NA angle, L1-NB dimension, L1-NB angle and IMPA angle. If dental decompensations and surgical success have some relationship were unknown. The L1-NB dimension, L1-NB angle, IMPA angle increased significantly after decompensation $(\mathrm{P}<0.05)$ and the IMPA angle was more approach to the norm at $\mathrm{T} 2$, which was important for the mandibular setback. In this study, only one patient finished with shallow overjet and overbite and the IMPA angle was only $84.5^{\circ}$ after the treatment. Maybe this was the reason for that and it indicated that whether the IMPA angle was normal after decompensation was crucial for the surgical treatment. Because of the uprighting of lower anterior teeth after decompensation, the reverse overjet was increased. That means the occlusal relationship and profile appearance will be even worse after decompensation, which increases the present discrepancy [22]. This has been proved in this study and it is necessary to explain this phenomenon to patients before treatment. Let patients understand this process will increase the moving distance of mandible in surgery and the final function and esthetic results will be much more satisfying. Johnston et al [3] reported that in their study, at pretreatment, the parameters most frequently outside the normal range were overjet, ANB, SNB and mandibular incisor inclination. The variable least frequently outside the normal range was maxillary incisor inclination. Although overjet correction was often successful, skeletal improvement was not as successful, with less than half having a final normal ANB measurement. Fifty-two percent still had excessive SNB angles at posttreatment. In this study, the average ANB angle after surgical was $-0.4^{\circ}$ and showed similar results. However, the overjet correction and the occlusion relationship were successful.

In clinic, the changes of incisor inclination as well as the arch width were important [23]. Usually the posterior upper arch of the severe Class III patients was narrow and needed to expand during the treatment. The decompensation of posterior teeth was as important as the anterior teeth and it was crucial for the posterior occlusal relationship after surgery. In this study, the increase in maxillary inter-first molar width were statistically significant $(\mathrm{P}<0.05)$ before and after dental 
decompensation of orthodontic treatment. While the mandibular intercanine width and inter-first molar width did not change significantly before and after treatment. This indicated that the proper overjet in the posterior teeth was very important for the stable occlusion relationship and can be as one criterion for the approprite dental decompensation.

\subsection{Consideration of the Relapsed Patients and Searching for the Reason}

More recent data [24,25] suggest that a skeletal relapse tendency maybe exist for mandibular prognathism patients between two month to one year after surgery. One year later after treatment all the patients were required to come back and gave the intraoral examinations. It was found that above 44 successful patients, two patients have minor relapse. The ANB angle of the two patients after treatment was $-0.7^{\circ}$ and $-0.9^{\circ}$ respectively. The IMPA angle was $85.5^{\circ}$ and $84.5^{\circ}$ respectively. The L1-NB distance was $4.5 \mathrm{~mm}$ and $4 \mathrm{~mm}$ and the L1-NB angle was $20.5^{\circ}$ and $19.5^{\circ}$ respectively. Comparation with Table 2, the landmarks about the lower incisors of two patients were under the average and very low. Maxillary inter-first molar width of the two patients was 55.3 $\mathrm{mm}$ and $55.5 \mathrm{~mm}$ respectively. So the value of IMPA angle, L1-NB distance and L1-NB angle were important and should not be very low. Also the maxillary expansion should be done well. Otherwise the overjet of posterior teeth was not normal and the relapse might be happen. Whether the ANB angle was normal may not be the criterion for the approprite dental decompensation. However, the reason about relapse was complex and further studies are required to discuss this problem.

\section{Conclusions}

The control of lower incisor inclination and maxillary arch width were important for correction of mandibular prognathism following mandibular setback surgery. Whether the IMPA angle was normal after decompensation was crucial for the surgical treatment. Also, the maxillary expansion was important in the surgical.

\section{References}

[1] Kelsey CC. Radiographic cephalometric study of surgically corrected mandibular prognathism. J Oral Surg 1968; 26: 239-48.

[2] Rabie AB, Wong RW, Min GU. Treatment in Borderline Class III Malocclusion: Orthodontic Camouflage (Extraction) Versus Orthognathic Surgery. Open Dent J 2008; 2: 38-48.

[3] Johnston C, Burden D, Kennedy D, Harradine N, Stevenson M. Class III surgical-orthodontic treatment: A cephalometric study. Am J Orthod Dentofacial Orthop 2006; 130: 300-309.

[4] Troy BA, Shanker S, Fields HW, Vig K, Johnston W. Comparison of incisor inclination in patients with Class III malocclusion treated with orthognathic surgery or orthodontic camouflage. Am J Orthod Dentofacial Orthop 2009; 135:
$146 \mathrm{e} 1-146 \mathrm{e} 9$.

[5] Solow B. The dentoalveolar compensatory mechanism: background and clinical implications. Br J Orthod 1980; 7: 145-161.

[6] Reitzik M. Cephalometry in the surgical correction of prognathism. Br J Oral Surg 1972; 10: 1-11.

[7] Ning F, Duan YZ, Huo N. Camouflage treatment in skeletal Class III cases combined with severe crowding by extraction of four premolars. Orthod Waves 2009; 68: 80-87.

[8] Aksu M, Kocadereli I. Arch Width Changes in Extraction and Nonextraction Treatment in Class I Patients. Angle Orthodontist 2005; 75: 948-952.

[9] Ning F, Duan YZ. Camouflage treatment in adult skeletal Class III cases by extraction of two lower premolars. Korean J Orthod 2010; 40: 349-357.

[10] Bell WH, Jacobs JD. Tridimensional planning for surgical orthodontic treatment of mandibular excess. Am J Orthod 1981; 80: 263-288.

[11] Litton SF, Ackermann LV, Isaacson RJ. A genetic study of Class III malocclusion. Am J Orthod 1970; 58: 565-577.

[12] Lee YS, Lee SJ, An H, Donatelli RE, Kim SH. Do Class III patients have a different growth spurt than the general population? Am J Orthod Dentofacial Orthop 2012; 142: 679-89.

[13] Alling CC. Orthognathic surgery: mandibular prognathism. J Ala Dent Assoc 1983; 67: 26-29, 32-35.

[14] Jacobson A, Evans WG, Preston CB. Mandibular prognathism. Am J Orthod 1974; 66: 140-171.

[15] Chen CM, Lee HE, Yang CF. Intraoral vertical ramus osteotomy for correction of mandibular prognathism: long-term stability. Ann Plast Surg 2008; 61: 52-55.

[16] Capelozza FL, Martins A, Mazzotini R. Effects of dental decompensation on the surgical treatment of mandibular prognathism. Int J Adult Orthodon Orthognath Surg 1996; 11: $165-180$.

[17] Bjork A. Some biological aspects of prognathism and occlusion of the teeth. Acta Odontal Scand 1950; 9: 1-40.

[18] Pascoe JJ, Haywars JR, Costich ER. Mandibular prognathism: its etiology and a classification. J Oral Surg Anesth Hosp Dent Serv 1960; 18: 21-24.

[19] Rakosi T, Schilli W. Class III anomalies: a coordinated approach to skeletal, dental and soft tissue problems. J Oral Surg 1981; 39: 860-870.

[20] Isaacon JR, Isaacon RJ, Speidel TM. Extreme variation in vertical facial growth and associated variation in skeletal and dental relations. Angle Orthod 1971; 41: 219-229.

[21] Lehman JA Jr, Tabbal N, Haas DG. The combined surgical and orthodontic treatment of mandibular prognathism. Ann Plast Surg 1981; 7: 458-463.

[22] Vasir NS, Thompson RT, Davies TM. Dental and skeletal changes following sagittal split ostotomy for correction of mandibular prognathism. Eur J Orthod 1991; 13: 134-142. 
[23] Zhou Y, Hu W, Fu M. Pre-and post surgical orthodontic treatment of mandibular prognathism. Zhonghua Kou Qiang Yi Xue Za Zhi 1999; 34: 357-360.

[24] Mobarak KA, Krogstad O, Espeland L, Lyberg T. Long-term stability of mandibular setback surgery: a follow-up of 80 bilateral sagittal split osteotomy patients. Int J Adult Orthodon Orthognath Surg 2000; 15: 83-95.

[25] Cho HJ. Long-Term Stability of Surgical Mandibular Setback. Angle Orthodontist 2007; 77: 851-856. 